\title{
A rice mutant with enhanced amylose content in endosperm without affecting amylopectin structure
}

\author{
Yasuhiro Suzuki $^{* 1)}$, Yoshio Sano ${ }^{2)}$, Kazuo Ise ${ }^{3)}$, Ushio Matsukura ${ }^{1,4)}$, Noriaki Aoki ${ }^{1{ }^{1}}$ and Hiroyuki Sato $^{1,5)}$ \\ 1) National Agriculture and Food Research Organization (NARO), National Institute of Crop Science, 2-1-18 Kannondai, Tsukuba, \\ Ibaraki 305-8518, Japan \\ 2) Graduate School of Agriculture, Hokkaido University, Kita 9, Nishi 9, Kita, Sapporo, Hokkaido 060-8589, Japan \\ 3) Japan International Research Center for Agricultural Sciences, 1-1 Ohwashi, Tsukuba, Ibaraki 305-8686, Japan \\ 4) National Agriculture and Food Research Organization (NARO), National Food Research Institute, 2-1-12 Kannondai, Tsukuba, \\ Ibaraki 305-8642, Japan \\ 5) Agriculture, Forestry and Fisheries Research Council, Ministry of Agriculture, Forestry and Fisheries, 1-2-1 Kasumigaseki, Chiyoda, \\ Tokyo 100-8950, Japan
}

\begin{abstract}
The $W x^{b}$ gene, one of the alleles at the rice waxy locus, responds to environmental temperatures during seed development and, as a result, the amylose content fluctuates and affects rice quality. Seeds of a low-amylose variety 'Snow Pearl' could be visibly distinguished depending on whether they matured in warm or cool temperatures; based on this, we isolated a mutant candidate, namely, the enhanced amylose content (ENA) mutant, which showed enhanced amylose content in the endosperm. The amylose contents of ENA mutants that matured at $20^{\circ} \mathrm{C}$ and $26^{\circ} \mathrm{C}$ were $6-7 \%$ higher than those of Snow Pearl. As the chain length distributions of amylopectin were almost identical between ENA and Snow Pearl, the mutation was not the amylose-extender mutation, but a new mutation that enhanced amylose content in the rice endosperm. Furthermore, ENA and Snow Pearl had a single nucleotide polymorphism on the third exon of the $W x$ gene and a single base change at the $5^{\prime}$ splice junction of the first intron specific to the $W x^{b}$ gene. Genetic analysis revealed that enhanced amylose content is controlled by 2 recessive genes. Thus, we isolated a rice mutant with enhanced amylose content in the endosperm without affecting the amylopectin structure. As global warming or higher maturation temperatures decrease the amylose content in rice endosperms, the mutant obtained in this study would be useful in breeding programs to diversify grain quality and to understand the genetic and molecular mechanisms of amylose synthesis.
\end{abstract}

Key Words: enhanced amylose content, global warming, net amylose, rice, warm temperatures, $W x$ gene.

\section{Introduction}

The amylose content of rice endosperm starch is an important characteristic that determines the consumption and cooking qualities of rice (Juliano 1992, Chikubu 1995), although different countries have prefer rice with varying amylose contents. The amylose content is genetically controlled by a major gene ( $W x$ gene, Nelson and Pan 1995) and is also affected by several modifying genes. In cultivated rice, 2 wild-type alleles, namely $W x^{a}$ and $W x^{b}$, predominate at the waxy locus, which encodes the granule-bound starch synthase that is responsible for amylose synthesis in the endosperm. Rice strains having the $W x^{b}$ gene contain 15-20\% amylose, whereas rice strains having the $W x^{a}$ gene contain 20-25\% amylose (Sano 1984). Moreover, the levels of $W x$ gene expression and amylose synthesis are controlled by

Communicated by S.-N. Ahn

Received January 29, 2008. Accepted April 21, 2008.

*Corresponding author (e-mail: suzuyasu@affrc.go.jp) other loci such as the $d u$ loci (Okuno et al. 1983). Mutation at the $d u$ loci results in decreased production of Wx protein, lowering amylose content in the endosperm (Yano et al. 1988, Hirano 1993).

In addition to genetic regulation, the environmental temperature during seed development also affects amylose synthesis in rice strains carrying the $W x^{b}$ allele. The levels of Wx protein decrease at higher temperatures, resulting in lower amylose content in mature seeds (Inatsu 1979, Asaoka et al. 1984, Sano et al. 1985). The amylose content thus varies with the year and site of cultivation, even for the same variety (Inatsu 1979, Asaoka et al. 1984). It is therefore important to evaluate the variation of starch characteristics in response to environmental temperatures and to develop rice varieties that do not alter their amylose content with environmental temperature.

The seeds of a low-amylose mutant can be visibly distinguished depending on whether they mature at cool or normal temperatures; based on this, we isolated a rice mutant insensitive to cool temperatures on amylose synthesis 
(Suzuki et al. 2002). Since global warming is a severe problem and higher temperatures affect rice quality and amylose content (Peng et al. 2004, Morita 2005), this method of using phenotypic changes could also be applied to isolate a rice mutant that has matured at a high temperature. In this paper, we describe the isolation and characterization of a rice mutant with enhanced amylose content in the endosperm without affecting the amylopectin structure.

\section{Materials and Methods}

\section{Plant materials and mutant screening}

To screen mutants with enhanced amylose content, we used a low-amylose rice variety 'Snow Pearl' (Higashi et al. 1999). Dry seeds of Snow Pearl rice were treated with $1 \mathrm{mM}$ sodium azide in $0.1 \mathrm{M}$ sodium phosphate buffer $(\mathrm{pH} 3.0)$ for $6 \mathrm{~h}$ at room temperature, followed by washing with tap water; they were then sown to grow $\mathrm{M}_{1}$ plants. The harvested $\mathrm{M}_{2}$ seeds were dehulled and, in certain cases, polished, and their seed transparency was compared with those of Snow Pearl and Nipponbare.

\section{Temperature treatment}

To investigate the response of the enhanced amylose content mutant (ENA) to environmental temperatures, growth chambers were used as previously described (Suzuki et al. 2002). After 5 days of anthesis, ENA and Snow Pearl plants were grown at $26^{\circ} \mathrm{C}$ and $20^{\circ} \mathrm{C}$ until seed maturation. To ascertain the genetic characteristics of ENA, $F_{2}$ and $F_{3}$ populations derived from a cross between ENA and another variety were matured at $26^{\circ} \mathrm{C}$ as described above. Mature seeds were polished, and $F_{2}$ and $F_{3}$ populations were segregated based on rice transparency.

\section{Amylose content, amylopectin structure, and Wx protein determination}

The amylose content of the samples was analyzed using an iodine colorimetric assay (Juliano 1971) with slight modifications (Suzuki et al. 2002). After starch was prepared from polished rice, the amylopectin chain length distribution in rice endosperm starch was analyzed by high-performance anion-exchange chromatography-pulsed amperometric detection (Dionex, Sunnyvale, CA, USA; Nagamine and Komae 1996, Suzuki et al. 2003). To estimate the amount of Wx protein, SDS-polyacrylamide gel electrophoresis and immunoblotting with antiserum against $\mathrm{Wx}$ protein were performed (Suzuki et al. 2002).

\section{DNA analysis}

Whole genomic DNA was extracted from young seedling leaves according to the cetyl trimethyl ammonium bromide (CTAB) method (Murray and Thompson 1980). The $W x$ gene sequence was amplified using primers described elsewhere (Bligh et al. 1998, Hirano et al. 1998, Sato and Nishio 2003). For the part of the $W x$ gene containing single nucleotide polymorphisms (SNPs) of Snow Pearl, gene- specific forward (5'-TGGCTGTAAGCACACACAAACT TCG-3') and reverse (5'-ACAGGTACGAGAGGGTGAG GTTTT-3') primers were used (Nippon Suisan Kaisha 2000). The polymerase chain reaction (PCR) product was gel-purified using a QIAquick gel extraction kit (Qiagen, Tokyo, Japan), and DNA sequencing was performed using a Big Dye Terminator Cycle Sequencing kit and an ABI PRISM 3100-Avant Genetic Analyzer (Applied Biosystems, Foster City, CA).

\section{Results}

Screening of the rice mutant with enhanced amylose content Since the amylose content profoundly affects the stickiness of cooked rice (Webb 1991, Chikubu 1995), a major objective of rice breeding is to develop rice varieties whose amylose content is not affected by temperature during seed maturation. We previously isolated a "coi" mutant insensitive to cool temperatures during seed development (Suzuki et al. 2002). The amylose content of coi seeds that matured at cool temperatures was almost identical to that of coi seeds at high temperatures. We crossed coi and non-glutinous varieties, but were unable to breed non-glutinous strains whose amylose content was not influenced by maturation temperatures (data not shown). Therefore, to screen a mutant that is characterized by unaltered amylose content in response to temperature changes, we used the low-amylose rice Snow Pearl as the mutagenized variety. Its amylose content was very low (approximately 5\%), and the endosperm appeared chalky when seeds were matured at normal temperature $\left(26^{\circ} \mathrm{C}\right)$ (Table 1 and Fig. 1A); however, when Snow Pearl seeds were matured at a cool temperature $\left(20^{\circ} \mathrm{C}\right)$, the amylose content was approximately $18 \%$, and the endosperm appeared semitranslucent. Because the amylose content of rice seed influences the degree of transparency (Suzuki et al. 2002), a mutant insensitive to the effect of normal (warmer) temperatures on amylose content and with (semitranslucent) seeds that mature at normal temperature should be easily distinguishable from the original variety that has low amylose (chalky) seeds; this is the basic principle for screening mutants whose amylose content remains unaltered in response to temperature changes.

The first screening was performed using $\mathrm{M}_{2}$ seeds that matured at an average temperature of $24^{\circ} \mathrm{C}$ to $26^{\circ} \mathrm{C}$ in a

Table 1. Amylose content (\%) of Snow Pearl, \#14 (ENA) and Koshihikari seeds matured at different temperatures. The seeds of each plant were matured at either 20 or $26^{\circ} \mathrm{C}$. The apparent amylose contents of the samples ( $20 \mathrm{mg}$ of white rice powder) were analyzed based on an iodine colorimetric assay. $\mathrm{n}=5$.

\begin{tabular}{lcr}
\hline \hline & $20^{\circ} \mathrm{C}$ & \multicolumn{1}{c}{$26^{\circ} \mathrm{C}$} \\
\hline Snow Pearl & $18.3 \pm 0.8$ & $5.2 \pm 0.5$ \\
$\# 14$ (ENA) & $24.7 \pm 0.3$ & $11.7 \pm 0.6$ \\
Koshihikari & $25.1 \pm 0.8$ & $17.0 \pm 0.3$ \\
\hline
\end{tabular}


A

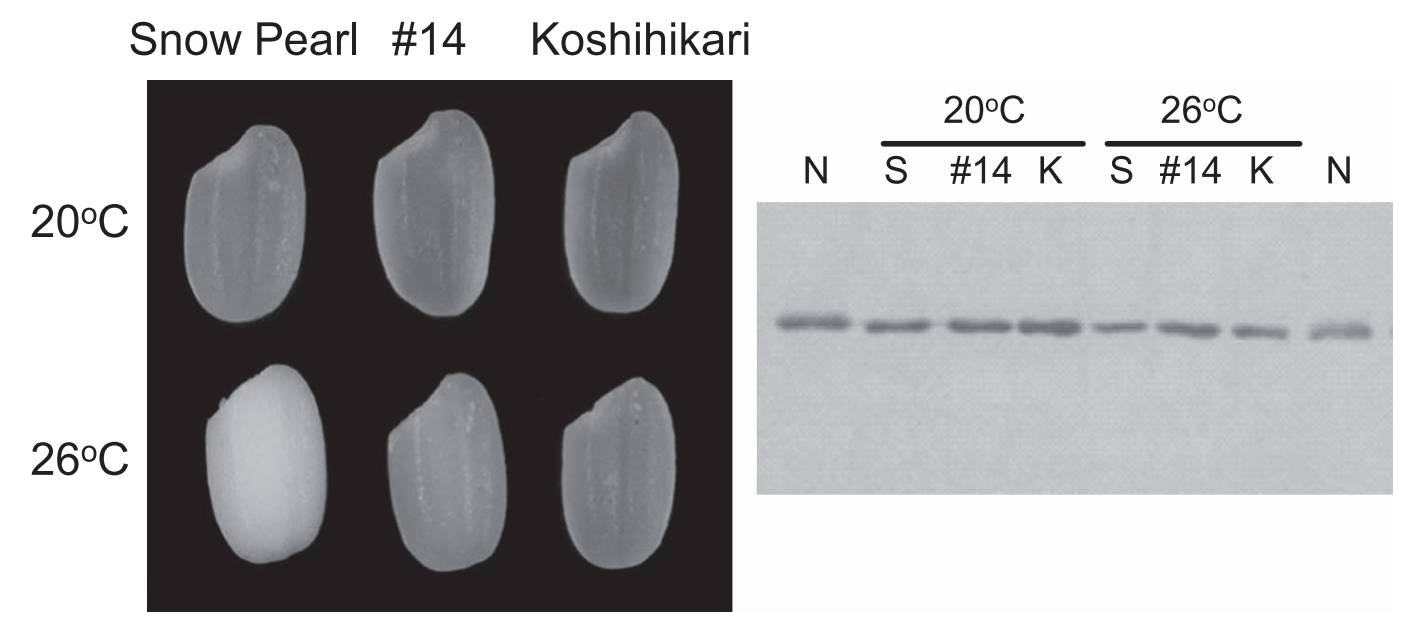

Fig. 1. Effect of maturation temperature on seed phenotypes and the amount Wx protein in the endosperm. (A) Seed phenotypes of Snow Pearl, \#14 (ENA), and Koshihikari. Rice seeds of each strain were matured at $26^{\circ} \mathrm{C}$ or $20^{\circ} \mathrm{C}$. (B) Immunoblotting analyses of Wx protein from Snow Pearl (S), \#14 (ENA) and Koshihikari (K) seeds matured at different temperatures. Seeds of each plant were matured at either $20^{\circ} \mathrm{C}$ or $26^{\circ} \mathrm{C}$ and were analyzed by immunoblotting using antiserum against rice Wx protein. N Nipponbare.

paddy field. A total of 7,200 $\mathrm{M}_{1}$ plants were examined. Although the panicles of almost all of these plants contained exclusively chalky seeds, one of these plants contained a mixture of chalky and semitranslucent seeds; therefore, semitranslucent $\mathrm{M}_{2}$ seeds were chosen as a mutant candidate (\#14) insensitive to maturation temperature during seed development. $\mathrm{M}_{2}$ seeds were seeded, and the amylose content of \#14 ( $\mathrm{M}_{3}$ seeds) was compared with that of Snow Pearl and Koshihikari using a temperature-controlled growth chamber. The amylose content of mature seeds of \#14 was approximately $12 \%$ at $26^{\circ} \mathrm{C}$ and $25 \%$ at $20^{\circ} \mathrm{C}$ (Table 1 ), indicating that \#14 responded to maturation temperatures in a similar manner to Snow Pearl with regard to amylose content, and it was 6-7\% higher in \#14. Furthermore, immunoblotting analyses using antiserum against $\mathrm{Wx}$ protein showed that the amount of Wx protein in each strain at $20^{\circ} \mathrm{C}$ was higher than that at $26^{\circ} \mathrm{C}$; moreover, the amount of Wx protein in \#14 at each temperature was higher than that in Snow Pearl. Thus, \#14 as well as the original Snow Pearl variety showed similar sensitivity to maturation temperatures with regard to amylose synthesis (Wx protein content and amylose content). On reflection, the phenotype of the endosperm in a rice mutant insensitive to higher maturation temperatures on amylose content was similar to that of a rice mutant whose amylose content increased despite its maturation temperature. Therefore, although we intended to screen a rice mutant whose amylose content did not decrease even though it matured at a higher temperature, we actually screened a mutant whose amylose content was enhanced. Hereafter, mutant \#14 is designated as ENA (enhanced amylose content) mutant line.

\section{Enhancement of net amylose content in the ENA mutant}

In this experiment, amylose content in the endosperm was determined by an iodine colorimetric method, which is rapid and simple for measuring a large number of samples (Juliano 1971). This method, however, has a tendency to overestimate the net amylose content in the case of long amylopectin chain-containing seeds (Baba 1986, Takeda et al. 1987); therefore, the amylose content was analyzed based on the method termed "apparent amylose." Yano et al. (1988) reported the amylose-extender (ae) mutant, which shows increasing levels of apparent amylose content. This increase in amylose content is caused by a dramatic reduction in the activity of the starch-branching enzyme IIb and an increase in the proportion of long amylopectin chains (Nishi et al. 2001). Hence, to clarify whether the amylose content in ENA was increased by the ae mutation, the amylopectin chain length distribution in rice endosperms was analyzed by high-performance anion-exchange chromatography (Fig. 2). The chain length distribution of amylopectin was almost identical between Snow Pearl and ENA, both of which matured at the same temperature. In addition, while the endosperm appearance of EM10 (an ae mutant) was usually floury (Satoh et al. 2003), that of ENA, as well as those of Snow Pearl and Koshihikari, was not (i.e., wild type). These results indicated that the mutation in ENA was probably not the ae mutation reported previously (Nishi et al. 2001), but a new mutation that enhanced the amylose content of the rice endosperm without affecting its amylopectin structure.

\section{Comparison of the $\mathrm{Wx}$ gene sequences}

Snow Pearl has an SNP on the third exon of the $W x$ gene, with a mutation from $\mathrm{G}$ to A (Nippon Suisan Kaisha 2000) (Fig. 3A), and the SNP is one of the causative genes 
A

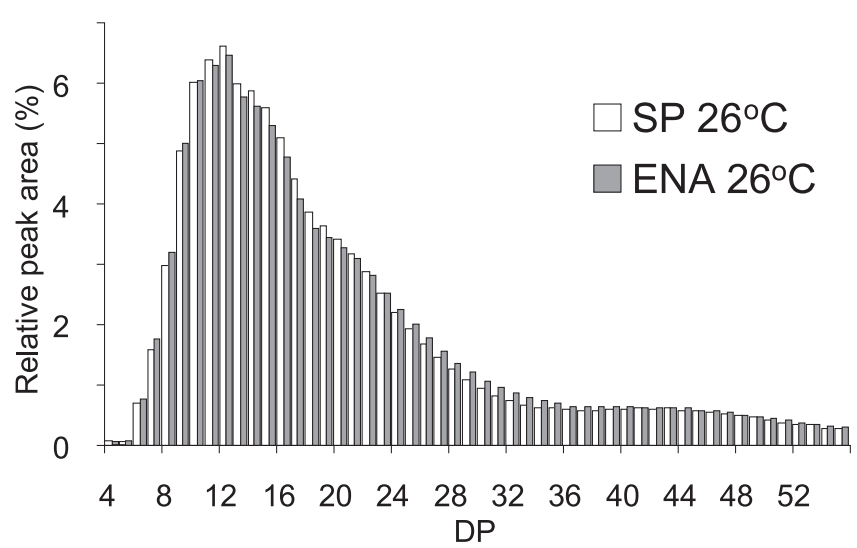

B

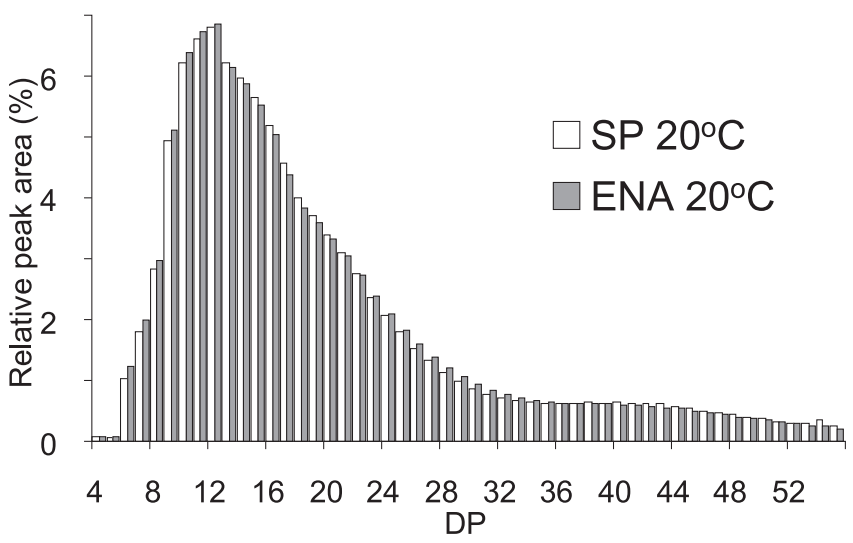

Fig. 2. The relative amount (\%) of $\alpha$-1,4-glucan chains of $\alpha$-polyglucans prepared from rice endosperms matured at either (A) $26^{\circ} \mathrm{C}$ or $(\mathrm{B}) 20^{\circ} \mathrm{C}$. DP Degree of polymerization of the chains, SP Snow Pearl.

of low amylose content in the endosperm. If the reverse mutation, i.e., from A to $\mathrm{G}$, occurred in the SNP in $\mathrm{M}_{0}$ seeds of mutagenized Snow Pearl, a rice mutant with enhanced amylose content could be screened; therefore, part of the ENA $W x$ gene (344 base pairs) containing the SNP was compared with those of Snow Pearl and Koshihikari (Fig. 3A). The SNP of ENA was identical to that of Snow Pearl but not to that of Koshihikari, indicating that factors other than the back mutation (A to $\mathrm{G}$ ) in the region of the $W x$ gene were responsible for the enhanced amylose content in the ENA mutant.

Second, we examined the other SNP at the $5^{\prime}$ splice junction of the $W x$ gene's first intron because the mutation from GG to GT results in low levels of mature transcripts as well as the gene product (Bligh et al. 1998, Hirano et al. 1998, Isshiki et al. 1998). Since Snow Pearl contains GT, it is possible that ENA contains GG; therefore, to examine the possibility that the increased level of amylose in ENA is due to the mutation from GT to GG at the $5^{\prime}$ splice junction, DNA fragments around the $5^{\prime}$ splice junction of the first intron in each strain were amplified by PCR, and the sequences were compared (Fig. 3B). The resulting sequences of fragments from Snow Pearl and ENA were identical. Furthermore, the nucleotide sequences of the $w x$ locus ( $W x$ gene and promoter region) of Snow Pearl and ENA were identical (data not shown). These results suggested that the back mutation from GT to GG in ENA did not occur and that the mutation in ENA was not on the $w x$ locus.

\section{Inheritance mode of the enhanced amylose content charac-} teristic

The mode of inheritance of the enhanced amylose content characteristic was analyzed by reciprocally crossing ENA with Snow Pearl. Seeds of Snow Pearl, ENA, and $F_{1}$ plants were matured at $26^{\circ} \mathrm{C}$. The distribution of amylose content in $\mathrm{F}_{2}$ seeds derived from reciprocal crosses fitted the ratio of 15 Snow Pearl-type seeds: 1 ENA-type seed (Fig. 4).

\section{A Snow Pearl ACGCTtgGaAtACCAGCGTT ENA ACGCTTGGAATACCAGCGTT \\ Koshihikari ACGCTTGGGATACCAGCGTT \\ B \\ Snow Pearl CATCTGCAAGTTATACATAT \\ ENA САTСTGCAАGTTATACATAT \\ Koshihikari CATCTGCAAGTTATACATAT \\ Lemont CATCTGCAAGgTATACATAT}

Fig. 3. Nucleotide polymorphisms on the third exon of the $W x$ gene (A) and the $5^{\prime}$ splice junction of the first intron (B). Arrow and bold characters indicate polymorphisms in specific regions.

We also examined segregations of $\mathrm{F}_{3}$ seeds from $85 \mathrm{~F}_{2}$ plants derived from a cross between ENA and Nipponbare based on the endosperm phenotype (seed transparency and amylose content) (Table 2). Although some $\mathrm{F}_{2}$ phenotypes could not be clearly distinguished, we found that at least $2 \mathrm{~F}_{2}$ plants (04F2-3 and 04F2-66) fitted the ratio of 0 Nipponbare-type $\mathrm{F}_{3}$ seeds: 15 Snow Pearl-type $\mathrm{F}_{3}$ seeds: 1 ENA-type $\mathrm{F}_{3}$ seed (Fig. 5). Type $\mathrm{H}$ will not be detected if it is controlled by $W x$ and 1 other gene but will be detected if it is controlled by $W x$ and 2 other genes (Table 2 and Fig. 5). Thus, the results of these $F_{2}$ and $F_{3}$ seeds from $F_{1}$ and $F_{2}$ plants, respectively, indicate that the enhanced amylose content characteristic of ENA mutants could be controlled by 2 recessive genes besides the $W x$ gene, and we isolated a new rice mutant (ENA) whose amylose content in the endosperm was enhanced, as compared with the original Snow Pearl variety. 

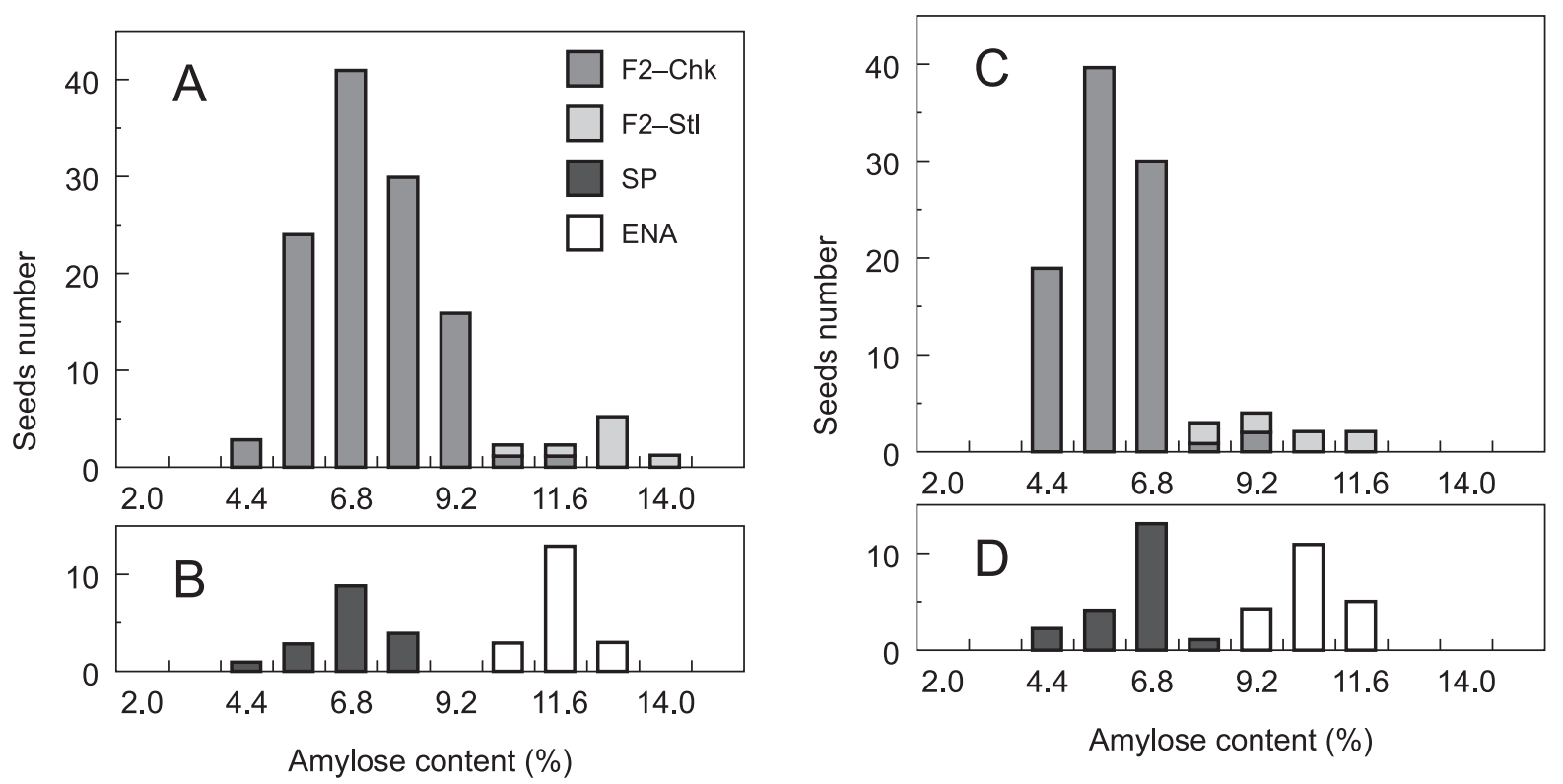

Fig. 4. Segregation of $F_{2}$ seeds derived from reciprocal crosses of Snow Pearl and ENA based on the seed amylose content. (A and C) $F_{2}$ seeds from the cross ENA $\times$ Snow Pearl and Snow Pearl $\times$ ENA. (B and D) Seeds of Snow Pearl and ENA. Each $F_{1}$ plant was grown and matured at $26^{\circ} \mathrm{C} . \mathrm{F}_{2}$ seeds of each $\mathrm{F}_{1}$ plant were segregated based on the seed amylose content, and their transparency was determined. For $\mathrm{F}_{2}$ seeds from the cross ENA $\times$ Snow Pearl, $\chi^{2}(15: 1)=0.52$ and $\mathrm{P}=0.47$. For $\mathrm{F}_{2}$ seeds from the cross Snow Pearl $\times \mathrm{ENA}, \chi^{2}(15: 1)=2.39$ and $\mathrm{P}=$ 0.12. F2-Chk chalky phenotype $F_{2}$ seeds, F2-Stl semitranslucent phenotype $F_{2}$ seeds, SP Snow Pearl.

Table 2. Expected segregation ratio of $F_{3}$ seeds derived from a cross between ENA and Nipponbare. $F_{3}$ seeds from $85 F_{2}$ plants derived from a cross between ENA and Nipponbare are classified based on their endosperm phenotype and amylose content; that is, wild type (Koshihikari), Snow Pearl type (Snow Pearl) and ENA type (ENA) (see Table 1 and Fig. 1A, $26^{\circ} \mathrm{C}$ ). Segregation types E and $\mathrm{H}$ will never be detected in a mutant controlled by 1 recessive gene other than the $W x$ gene but in a mutant controlled by 2 recessive genes other than the $W x$ gene.

\begin{tabular}{|c|c|c|c|c|c|c|c|c|}
\hline \multirow{3}{*}{ Type } & \multicolumn{3}{|c|}{ Segregation ratio of $\mathrm{F}_{3}$ seeds } & \multicolumn{2}{|c|}{$\begin{array}{l}\text { Expected segregation ratio of } \mathrm{F}_{2} \\
\text { plants by additional genes besides } W x\end{array}$} & \multicolumn{3}{|c|}{ Segregation ratio of $\mathrm{F}_{2}$ plants } \\
\hline & \multirow{2}{*}{ wild type } & \multirow{2}{*}{$\begin{array}{l}\text { Snow Pearl } \\
\text { type }\end{array}$} & \multirow{2}{*}{ ENA type } & \multirow{2}{*}{ 2-genes } & \multirow{2}{*}{ 1-gene } & \multirow{2}{*}{ Observed $^{a}$} & \multicolumn{2}{|c|}{ Expected } \\
\hline & & & & & & & 2-genes & 1-gene \\
\hline A & 1 & 0 & 0 & 16 & 4 & 22 & 21.3 & 21.3 \\
\hline $\mathrm{B}^{b}$ & 3 & 1 & 0 & 14 & 2 & \multirow{4}{*}{37} & \multirow{4}{*}{42.5} & \multirow{4}{*}{42.5} \\
\hline $\mathrm{C}^{b}$ & 3 & 0 & 1 & 2 & 2 & & & \\
\hline $\mathrm{D}^{b}$ & 12 & 3 & 1 & 8 & 4 & & & \\
\hline $\mathrm{E}^{b}$ & 48 & 15 & 1 & 8 & 0 & & & \\
\hline $\mathrm{F}^{c}$ & 0 & 1 & 0 & 7 & 1 & \multirow{4}{*}{26} & \multirow{4}{*}{21.3} & \multirow{4}{*}{21.3} \\
\hline $\mathrm{G}^{c}$ & 0 & 3 & 1 & 4 & 2 & & & \\
\hline $\mathrm{H}^{c}$ & 0 & 15 & 1 & 4 & 0 & & & \\
\hline $\mathrm{I}^{c}$ & 0 & 0 & 1 & 1 & 1 & & & \\
\hline Total & & & & 64 & 16 & 85 & 85.0 & 85.0 \\
\hline
\end{tabular}

\section{Discussion}

In these studies, we isolated a rice mutant, ENA, whose amylose content in the endosperm was enhanced without effecting the amylopectin structure (Table 1 and Fig. 2). With respect to amylose synthesis, the suppression of $W x$ gene expression or the reduction of amylose content has been studied extensively (Okuno et al. 1983, Sato 2002, Satoh et al. 2003, Suzuki 2006, Ando et al. 2007), but genes that enhance the amylose content in seeds have not been described. Thus far, the apparent amylose content-enhancing mutations reported were GG/GT in the 5' splicing site of the first intron in the Wx gene (Bligh et al. 1998, Hirano et al. 1998, Isshiki et al. 1998) and the ae mutation in the starch-branching 

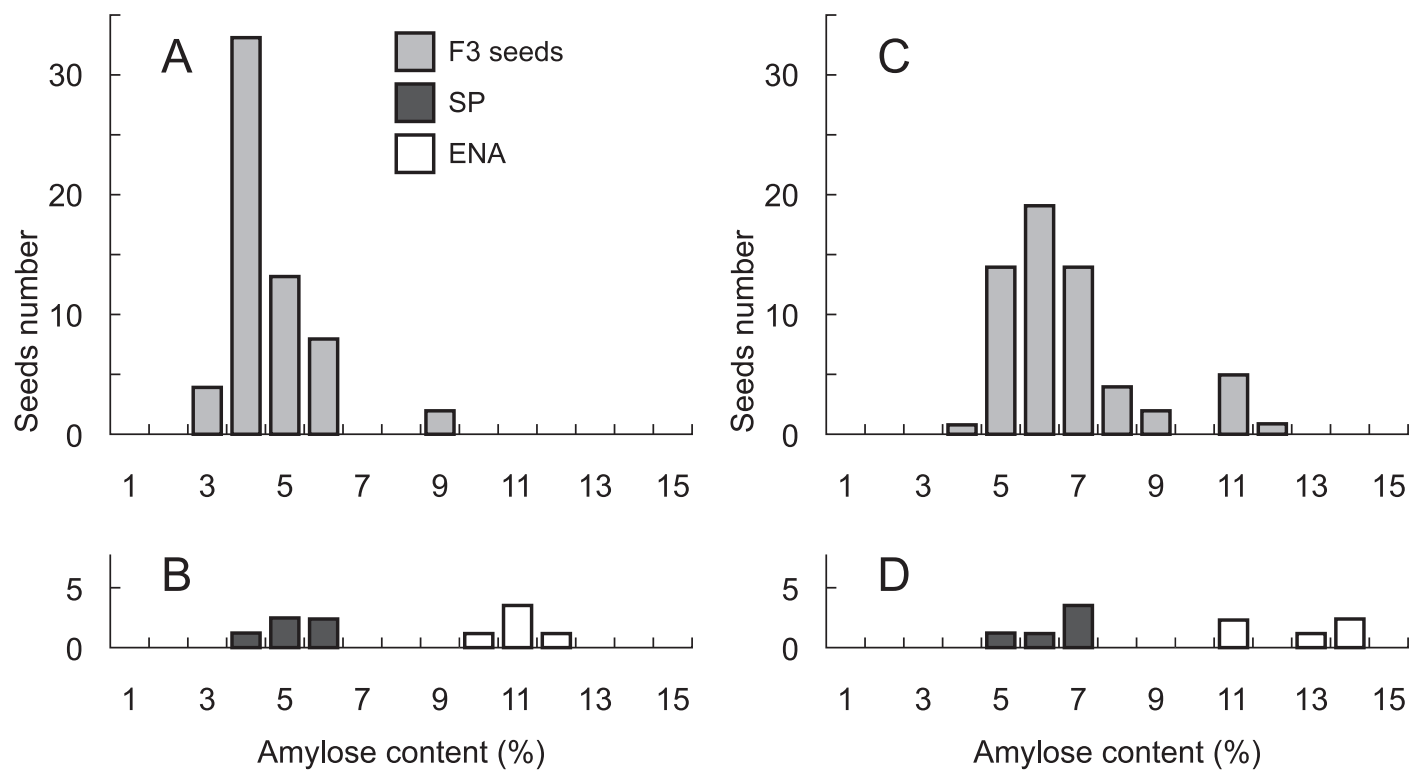

Fig. 5. Segregation of $\mathrm{F}_{3}$ seeds from $\mathrm{F}_{2}$ plants $(04 \mathrm{~F} 2-3$ and $04 \mathrm{~F} 2-66)$ that were derived from crosses between ENA and Nipponbare based on the amylose content. $\mathrm{F}_{3}$ seeds are represented as 04F2-3 (A) and 04F2-66 (C). (B) and (D) indicate the results for Snow Pearl and ENA. Each $\mathrm{F}_{1}$ plant was grown and matured at $26^{\circ} \mathrm{C} . \mathrm{F}_{3}$ seeds of each $\mathrm{F}_{2}$ plant were segregated based on their amylose content. For $\mathrm{F}_{3}$ seeds from $04 \mathrm{~F} 2-3, \chi^{2}(15: 1)=0.87$ and $\mathrm{P}=0.35$. For $\mathrm{F}_{3}$ seeds from $04 \mathrm{~F} 2-66, \chi^{2}(15: 1)=1.44$ and $\mathrm{P}=0.23$. SP Snow Pearl. Because all $\mathrm{F}_{3}$ seeds were low amylose chalky grains and enhanced amylose semitranslucent grains, seeds of Snow Pearl and ENA were used as references.

enzyme IIb (Yano et al. 1988, Nishi et al. 2001). GG, however, drastically enhances the quantity of Wx protein as well as the amylose content in the endosperm as compared with GT. In ae mutants, the higher apparent amylose content is not caused by an increase in net amylose content but by an increase in long amylopectin chains (Nishi et al. 2001). Thus, both the replacement of GT with GG and the ae mutation cause a significant increase in the amylose content and significantly alter consumption quality. On the other hand, the mutant ENA enhances amylose content in the rice endosperm without affecting its amylopectin structure (Table 1 and Fig. 2); therefore, the unique characteristics of ENA could be advantageous in producing a greater number of rice varieties of high yield and good quality.

To use ENA as the mother strain for breeding new varieties, we have to consider that the enhanced amylose content characteristic of ENA was regulated by 2 recessive genes, i.e., by multiple genes (Table 2, Fig. 4 and Fig. 5), other than the $W x$ genes. To breed new low amylose rice varieties with enhanced amylose content as parent lines, we could easily distinguish low amylose chalky grains from enhanced amylose semitranslucent grains on the basis of endosperm transparency (Fig. 1, at $26^{\circ} \mathrm{C}$ ); however, we could not breed new medium- and high-amylose rice varieties with enhanced amylose content as parent lines because endosperm transparency could not be used as a simple and easy screening method for distinguishing ena alleles. Recently, we have been isolating some strains with 1 of the 2 recessive, multiple genes. Using these strains, it might be possible to map the ena character and breed new varieties with enhanced amylose content grains. At the same time, this ena character would be useful for understanding the genetic and molecular mechanisms of amylose synthesis.

It should also be noted that rice quality is related to global warming. Annual mean temperatures have increased over the last few decades, and the mean temperature during the dry cropping season and the corresponding rice grain yield have been closely linked (Zakaria et al. 2002, Peng et al. 2004). In Japan, high maturation temperatures are severely affecting the quality of rice; with regard to rice appearance, the presence of a white core and milky white color, etc., have been observed (Matsumura 2005, Morita 2005). Furthermore, higher environmental temperatures during seed development are also causing a decrease in the amylose content (Asaoka et al. 1984, Suzuki 2006). As lower amylose content increases the stickiness of rice, the consumption quality of some varieties fluctuates; therefore, ENA could be a valuable parent strain for enhancing the amylose content of grains under warmer cultivation conditions. In addition, we should also note that other seed components of many crops are affected by warmer temperatures. As observed with regard to the amylose content of rice seeds, warmer temperatures during seed development decrease the anthocyanin content of dark purple rice (Kobayashi et al. 2001), the red color of apples (Sugiura 2002), and the purple color of eggplants (Nothmann et al. 1978). If the genes responsible for the ena phenotype were identified and found to resemble the genes decreasing the other seed components, ena genes could be effective to increase the levels of seed components like anthocyanin and thus improve the quality of these crops. 


\section{Acknowledgments}

We thank H.-Y. Hirano (School Sci., Univ. Tokyo) for providing the antibodies and his invaluable advice, K. Komae (Natl. Inst. Crop Sci.) for his invaluable advice and S. Sakurai (Natl. Inst. Crop Sci.) for her technical assistance. This work was supported in part by the Research Project for the New Rice Era, Ministry of Agriculture, Forestry and Fisheries of Japan.

\section{Literature Cited}

Ando,I., H. Araki, H. Shimizu, M.Kuroki, K.Miura, K. Nagano and K. Konno (2007) "Oborozuki", a new rice cultivar with low amylose content and superior eating quality. Res. Bull. Natl. Agric. Res. Cent. for Hokkaido Reg. 186: 31-46.

Asaoka,M., K.Okuno, Y.Sugimoto, J.Kawakami and H.Fuwa (1984) Effect of environmental temperature during development of rice plants on some properties of endosperm starch. Starch/ Stärke 36: 189-193.

Baba,T. (1986) Determination of amylose and amylopectin in starch. In: Nakamura, M. and K.Kainuma (eds.) Laboratory methods for starch and related carbohydrate, Japan Scientific Societies Press, Tokyo, pp. 89-94.

Bligh,H.F.J., P.D.Larkin, P.S.Roach, C.A.Jones, H.Fu and W.D.Park (1998) Use of alternate splice sites in granule-bound starch synthase mRNA from low-amylose rice varieties. Plant Mol. Biol. 38: 407-415.

Chikubu, S. (1995) Seasoning of cooked rice. In: Ishitani, T. and K. Ohtsubo (eds.) Science of rice, Asakura Publishers, Tokyo, pp. 117-137.

Higashi, T., S. Saitoh, T. Takita, M. Yamaguchi, Y. Sunohara, N.Yokogami，R.Ikeda，Y.Tamura，Z.Oyamada，H.Kowata, M.Inoue, S.Matsumoto and T.Kataoka (1999) Breeding of a new rice cultivar with low amylose contents "Snow Pearl". Bull. Tohoku Natl. Agric. Exp. Stn. 95: 1-12.

Hirano,H.-Y. (1993) Genetic variation and gene regulation at the wx locus in rice. Gamma-Field Symp. 24: 63-79.

Hirano,H.-Y., M.Eiguchi and Y.Sano (1998) A single base change altered the regulation of the Waxy gene at the post-transcriptional level during domestication of rice. Mol. Biol. Evol. 15: 978-987.

Inatsu, O. (1979) Improvement of the quality of rice grown in Hokkaido. J. Jpn. Soc. Starch Sci. 26: 191-197.

Isshiki, M., K. Morino, M.Nakajima, R.J. Okagaki, S.R. Wessler, T.Izawa and K. Shimamoto (1998) A naturally occurring functional allele of the rice waxy locus has a GT to TT mutation at the 5' splice site of the first intron. Plant J. 15: 133-138.

Juliano,B.O. (1971) A simplified assay for milled-rice amylose. Cereal Sci. Today 16: 334-340.

Juliano, B.O. (1992) Structure, chemistry, and function of the rice grain and its fractions. Cereal Foods World 37: 772-779.

Kobayashi,A., H.Shimizu and M.Kuroda (2001) Effect of mean air temperature during ripening period on pigment contents of dark-purple rice. Hokuriku Crop Sci. 36: 33-35.

Matsumura,O. (2005) The quality damage in rice grain under high temperature during ripening, That background and countermeasure. J. Agric. Sci. 60: 442-446.

Morita, S. (2005) The occurrences of immature grain with white portions and deep ditch, and grain weight decrease in rice under high temperature during ripening. J. Agric. Sci. 60: 437-441.

Murray,M.G. and W.F.Thompson (1980) Rapid isolation of high mo- lecular weight plant DNA. Nucleic Acids Res. 8: 4321-4325.

Nagamine, T. and K.Komae (1996) Improvement of a method for chain-length distribution analysis of wheat amylopectin. J. Chromatography A. 732: 255-259.

Nelson, O. and D.Pan (1995) Starch synthesis in maize endosperms. Ann. Rev. Plant Physiol. Plant Mol. Biol. 46: 475-496.

Nippon Suisan Kaisha, Co. (2000) A method to discriminate a specific low-amylose rice variety. Japanese published unexamined application 2000-201679.

Nishi,A., Y.Nakamura, N.Tanaka and H.Satoh (2001) Biochemical and genetic analysis of the effects of amylose-extender mutation in rice endosperm. Plant Physiol. 127: 459-472.

Nothmann,J., I.Rylski and M.Spigelman (1978) Effect of air and soil temperatures on colour of eggplant fruits (Solanum melongena L.). Expl. Agric. 14: 189-195.

Okuno,K., H.Fuwa and M.Yano (1983) A new mutant gene lowering amylose content in endosperm starch of rice, Oryza sativa L. Jpn. J. Breed. 33: 387-394.

Peng, S., J.Huang, J.E.Sheehy, R.C.Laza, R.M.Visperas, X.Zhong, G.S.Centeno, G.S.Khush and K.G.Cassman (2004) Rice yields decline with higher night temperature from global warming. Proc. Natl. Acad. Sci. USA 101: 9971-9975.

Sano, Y. (1984) Differential regulation of waxy gene expression in rice endosperm. Theor. Appl. Genet. 68: 467-473.

Sano,Y., M.Maekawa and H.Kikuchi (1985) Temperature effects on the Wx protein level and amylose content in the endosperm of rice. J. Hered. 6: 221-222.

Sato,H. (2002) Genetics and breeding for good quality rice. The present and the prospects of low amylose rice breeding. Agricul. Horticul. 77: 556-564.

Sato,Y. and T.Nishio (2003) Mutation detection in rice waxy mutants by PCR-RF-SSCP. Theor. Appl. Genet. 107: 560-567.

Satoh,H., A.Nishi, K.Yamashita, Y.Takemoto, Y.Tanaka, Y.Hosaka, A.Sakurai, N.Fujita and Y.Nakamura (2003) Starch-branching enzyme I-deficient mutation specifically affects the structure and properties of starch in rice endosperm. Plant Physiol. 133: $1111-1121$.

Sugiura, T. (2002) Influence of global warming on fruit tree production environment and research problems. J. Agricul. Research. 24: 23-30.

Suzuki,Y. (2006) Variation of rice amylose content. Mechanism and regulation. Agricul. Horticul. 81: 183-190.

Suzuki,Y., Y.Sano and H.-Y.Hirano (2002) Isolation and characterization of a rice mutant insensitive to cool temperatures on amylose synthesis. Euphytica 123: 95-100.

Suzuki,Y., Y.Sano, T.Ishikawa, T.Sasaki, U.Matsukura and H.-Y. Hirano (2003) Starch characteristics of the rice mutant du2-2 Taichung 65 highly affected by environmental temperatures during seed development. Cereal Chem. 80: 184-187.

Takeda,Y., S.Hizukuri and B.O.Juliano (1987) Structure of rice amylopectins with low and high affinity for iodine. Carbohydr. Res. 168: 79-88.

Webb, B.D. (1991) Rice quality and grades. In: Luh,B.S. (ed.) Rice. Vol. II. Utilization (2nd Ed.), AVI Book, New York, pp. 89-119.

Yano,M., K.Okuno, H.Satoh and T.Omura (1988) Chromosomal location of genes conditioning low amylose content of endosperm starches in rice, Oryza sativa L. Theor. Appl. Genet. 76: 183189.

Zakaria,S., T.Matsuda, S.Tajima and Y.Nitta (2002) Effect of high temperature at ripening stage on the reserve accumulation in seed in some rice cultivars. Plant Prod. Sci. 5: 160-168. 